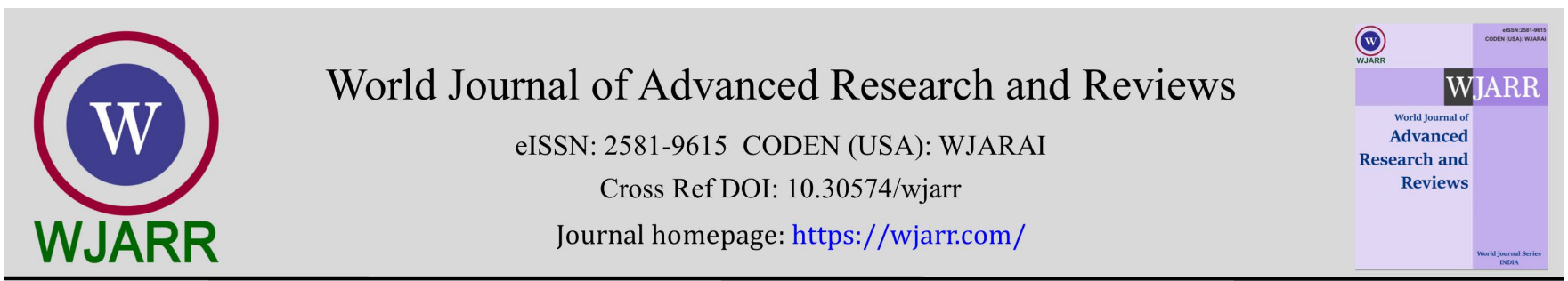

(RESEARCH ARTiClE)

\title{
How economic sustainability is affected by innovation performance and sustainable manufacturing
}

\author{
Kashif Akbar* \\ Department of Commerce, Bahauddin Zakariya University, Multan, Punjab, Pakistan.
}

World Journal of Advanced Research and Reviews, 2021, 11(01), 247-255

Publication history: Received on 25 June 2021; revised on 30 July 2021; accepted on 02 August 2021

Article DOI: https://doi.org/10.30574/wjarr.2021.11.1.0350

\begin{abstract}
The improvement of the possibility of sustainability demonstrates an emotional development in worldwide reasoning that powers organizations to reevaluate the manner in which they work. To upgrade financial turn of events, organizations need to reinitiate and receive more coordinated manageable practices to reestablish their organization technique. Sustainable manufacturing practices (SMP), as considered as intra-and Inter-authoritative performs that coordinate natural, monetary and communal components in functional and commercial activities, will work on corporate execution, earlier investigations accept. This article is pointed toward dissecting that how impact SMP affects economic sustainability (EST) and interceded that how SMP affects EST over innovation performance (IPR). This article investigations exactly the connection between SMP, IPR (item, measure, sorting out and promoting) and EST utilizing review information acquired from 140 fabricators from Pakistan. The investigation uncovered that the inward SMP well affects EST and interaction advancement intercedes incompletely this interior SMP-EST relationship. The exploration embraced the PLS-SEM approach. Shockingly, despite the fact that here is not any substantial association among external SMP and EST, the significance of the relationship has modified with the consolidation into this connection of item and interaction advancements. The investigations have commonly exhibited the significance of SMP and IPR in affecting financial execution tentatively. It is subsequently prompted that organizations ought to expressly recognize the financial potential accomplished from being socially mindful or naturally agreeable, instead of depending on benevolent feelings or responding to outside pressures.
\end{abstract}

Keywords: Innovation performance; Sustainability; Sustainable Manufacturing Practice; Economic Sustainability; Sustainable Manufacturing

\section{Introduction}

Sustainable manufacturing (SM) strategies have stood out because of rising overall worries on manageability issues like lack of normal assets, quick ecological disintegration, uncalled for social equilibrium and serious worldwide intensity. The thought of sustainability has affected the personality of corporate action essentially. As individuals keep on pursuing a more noteworthy personal satisfaction, fabricating organizations have a critical test to deliver more things while using less assets and less contamination and waste generated [1].

To seek after items and friends exercises in a naturally cordial manner and be socially dependable would increment functional efficiency [2] and give cutthroat benefits [3]. While a few specialists found that sustainable manufacturing practice (SMP) affects accomplishing economic sustainability (EST), different researchers neglected to accomplish this[4,5]. The conflicting discoveries may be identified with the absence of meaning of the SMP and EST context oriented parts. Inadequate factual proof to help a significant SMP-EST connect shows that these two factors may have a more

\footnotetext{
${ }^{*}$ Corresponding author: Kashif Akbar

Department of Commerce, Bahauddin Zakariya University, Multan, Punjab, Pakistan.

Copyright (c) 2021 Author(s) retain the copyright of this article. This article is published under the terms of the Creative Commons Attribution Liscense 4.0.
} 
confounded communication. The motivation behind the current examination is to analyze SMP's effect on EST using observational information assembled by Pakistani organizations.

The rest of this study is masterminded appropriately. In Section 2, literature is talked about and research hypotheses concerning the interrelations between SMP, IPR and EST are created. Section 3 portrays the methodological way to deal with the exact investigation. Section 4 gives results and remarks, and in Section 5 there are ends with hypothetical and pragmatic outcomes.

\section{Literature Review and Research Hypotheses}

\subsection{Sustainable Manufacturing Practices (SMP)}

Albeit the writing examines SM widely, the idea isn't generally accepted [6]. Before, a few researchers considered SM as procedures of creation or innovations zeroing in all the while on monetary development and the preservation of the environment [7,8]. SM has been described as the creation of made merchandise that utilization non-dirtying, energy and regular assets protecting techniques and that are monetarily solid, ok for representatives, networks and clients, by stretching out their inclination to make supportability harmless to the ecosystem. This examination depicts SM as the wide thought that has been set up through the joining of supportability standards into an assembling framework to accomplish maintainability in modern creation, advancing social prosperity just as pointing monetary and ecological advantages.

The development of Sustainability and SM ideas brought about a scope of SMP, from the utilization of contamination the executives innovation toward the finish of the line to more incorporated creation frameworks, which empower participation between utilitarian areas in the organization and between associations, for example, shutting circle creation and modern symbiosis [6]. SMP advancement frequently happens at three levels, to be specific item, interaction and system[10].The item has been changed into a more feasible 6R procedure (reduce, recycle, reuse, remanufacture, redesign, recover) which changes the worldview from single life to numerous life cycles [23]. On an item level, customary 3R thought (recycle, reuse, reduce) has become more solid 6R strategies. Moreover, the framework's direction is developed from a hierarchical to a whole store network, and past the creation chain [10, 11], despite the fact that various cycle steps have been made to streamline mechanical enhancements and to design cycles to lessen asset utilization, squander age and word related dangers just as further develop item life.

Considering SM its set of experiences, SMP might be portrayed as the intra-and between hierarchical acts of an organization that incorporates ecological, monetary and social components in business exercises and tasks. Here are 2 kinds of SMP, external SMP and internal SMP, separated relying upon the bearing of economical reasoning. While internal SMP centers around maintainable practice inside an organization, external SMP alludes to between office exercises both inside or more the worth framework to advance simultaneously monetary, natural and social supportability.

\subsection{Economic Sustainability (EST) and SMP}

After resource-based view (RBV) it's anything but an upper hand and thus add to higher performance [12]. SMP addresses the capability based way to deal with the improvement of products and cycles for longer-term supportability, utilizing an assortment of assets inside and outside the business. Such natural and socially mindful exercises would enjoy a cutthroat benefit that will improve the organization's prosperity. Various investigations in various states have shown that remembering social and natural issues for specialized and hierarchical activities did by organizations will further develop financial execution $[5,13,14,15]$.

Rocketing into each SMP measurement, a few exploration have approved inside SMP's ability to further develop EST. For instance, an observational review led in 212 US fabricating organizations on the supportable stockpile chain [2] shows that manageability rehearses in tasks and market the board would upgrade monetary, and business execution. In designated at the energy proficiency, water protection, squander and different assets decrease, organizations can increment functional effectiveness, for example, costs reserve funds, diminished lead times and better quality and usefulness, just as upgrades in pay or benefit, portion of the overall industry and the standing of energy productivity and effectiveness in lessening environment execution [5,13,14]. Then again, experimental exploration [16] shows that the directions of representatives are more viable than those of other essential partners, for instance customers, providers, networks, and investors on organization monetary achievement. The aftereffects of prior investigations affirms these significant outcomes, which affirms the valuable impact on organization and business accomplishment on the worker relationship $[17,18]$. 
For external SMP, past research enjoy recognized diverse monetary benefits for organizations through commitment with outer partners and their contribution in them. The great and substantial straight influence of corporate social obligation toward organizations on serious accomplishment among 67 medium to enormous firms [19] has been shown, for instance, to be gainful. The greening, greening inbound and greening outbound overview shows that the greening inbound, greening and greening outbound outcomes in critical incentive for further developing proficiency, quality and efficiency and furthermore cost investment funds, new market openings and higher item costs, net revenue, deals and market extent. Some extra examinations affirmed these outcomes, which show the valuable associations between external SMP and EST [5, 14, 15]. The end of waste will have significant effects in expanding functional greatness and creation limit on executing shut inventory network procedures for both forward and switched shut circle initiatives [21]. The following hypotheses are suggested according to the existing experimental results buttressed by the RBV philosophy:

H1A: Internal Sustainable Manufacturing Practices (SMP) positively impacts Economic Sustainability (EST).

H1B: External Sustainable Manufacturing Practices (SMP) positively impacts Economic Sustainability (EST).

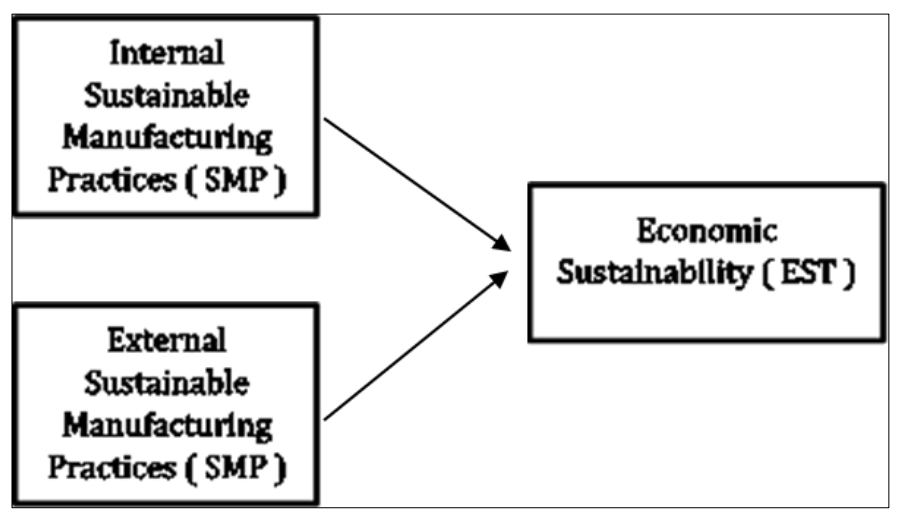

Figure 1 Research Model 1

\subsection{Economic sustainability (EST), Sustainable Manufacturing Practice (SMP) and Innovation Performance (IPR)}

Sensitive and socially responsible environmental policies would generate competitive advantages that improve competitiveness in companies and ultimately achieve better enactment. Fragment and part of SMP is the distribution of knowledge among companies and other inner and outdoor stakeholders, allowing the company to increase the performance of its innovation [22,23], which in shot would result in secure success.

Companies must proactively acclimatize to fluctuations in the business situation by continuously updating their goods, procedures and society [24] in order to guarantee their survival and growth in a volatile market climate. Within this company the capacity to execute creative ideas effectively brings substantial advantage to the achievement of increased EST in the recognizing of innovation as important, scarce, non-substitute and distinctive organizational resources. In today's literature [24,25,26], we have wide recognition and extensively of the relevance of product, organizational, process, and advertising innovation for ornamental company presentation.

Although product, organizational, process, and advertising innovations should have an influence on EST, various kinds or mixtures of these innovations might provide varied results [27, 28]. The larger IPR notion that is proposed for mediating the causal link between EST and SMP, as particularly described in the subsequent hypotheses, should thus be appropriately taken into account all these developments:

H2A: Innovation Performance (IPR) mediates the association among Economic Sustainability (EST) and Internal Sustainable Manufacturing Practice (SMP)

H2B: Innovation Performance (IPR) mediates the association among Economic Sustainability (EST) and External Sustainable Manufacturing Practice (SMP) 


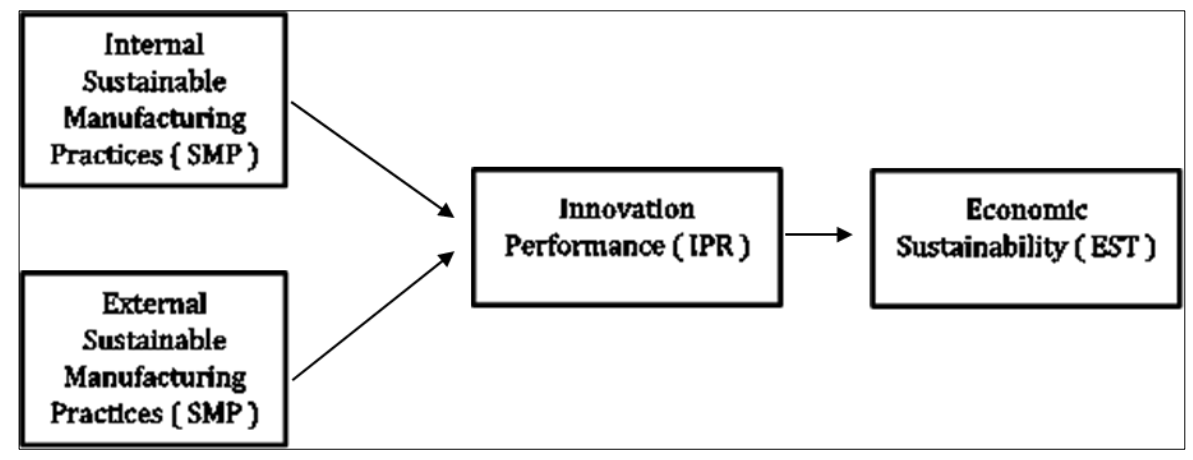

Figure 2 Research Model 2

\section{Research Methodology}

\subsection{Data Collection and Sampling}

Initially a questionnaire was sent to 200 prospective responders using a survey-based technique. 6 are returned as unproductive, lowering sample frame to 194 out of the total questionnaires given. All non-respondents were surveyed one month earlier in a second wave. The survey showed 140 acceptable replies, or 70 percent of respondents, after 4 unfinished forms and 2 for severe outliers were discarded.

The majority of the companies, receiving answers from numerous production industries, are from four industries : chemical industry (9.0\%), transportation (14.2\%), electronics (19.2\%) and metal industry (7.0\%), while the remaining $20.6 \%$ are from the food, wood, machining, clothing and textiles sectors. Some $62 \%$ of responding companies are big, while $23 \%$ and $19 \%$ are small and medium-sized organizations.

In order to detect possible no response bias in this study, an self-governing crowd t-test and Chi-square test carried out. T-tests are carried out for all measuring elements imitating SMP, IPR and EST. The consequences do not reveal substantial variations among primary and dawn (indicating non-responsible) responders on apiece element being experienced. Likewise, in terms of categorization and corporate size the chi-square analysis does not show any substantial alterations among the 2 sets of defendants. Since this research is based on self-reported facts and answers from one individual respondent per company, a one factor test was undertaken by Harman to determine the presence of common biases in the approach. But the result is not significant, which implies a substantial technique bias not confusing the interpretation of the conclusions of this investigation. A complete data set of 140 replies is therefore legitimate and may be used to evaluate theorized associations in research.

\subsection{Statistical Analysis}

In this work, partially the least squared structural equation modelling (PLS-SEM) was employed in the evaluation of a number of hypothesized models, with the capacity to concurrently test extra complicated route replicas including a greater quantity of variables [27,28]. Measurement model and structural model are evaluated independently following the two-stage procedure of evaluation of the PLS-SEM model.

\subsection{Measurement Variables}

Build operationalization depends on the joining of scales made by earlier investigators for both endogenous and exogenous factors. Notwithstanding, because of the shortfall of characterized scales, a few models, for example, Etl5 industrial relations and IPR3 managerial innovation are self-controlled. Indicators are set up painstakingly dependent on the hypothetical idea relating to each building.

In start SMP first conceived on the foundation of [6, 10], and 2 exogenous dormant variables, specifically external SMP and internal SMP, are investigated. Though three inner structures (i.e., cleaner Itl1, eco-efficiency Itl2 and working relationship Itl3) are tested for internal SMP, five structures were utilized to measure the exterior SMP (i.e. Etl1 dealer relations, Etl2 client relations, Etl3 public relations, Etl4 closed-loop manufacturing, and Etl5 engineering relations). The respondents should identify the extent of settlement or dissimilarity with 28 SMP indicators, which they believe to be relevant to their organization's existing practice, applying a five-point scale specified that 1 is strongly opposed to 5 . 
Economic Sustainability (EST) assesses to what degree a company in the previous three years recovers working and commercial performance. In the form of 7 indicators, the responder is again invited to pick a response on a five-point scale for each indicator, given the substantial discrepancy of one for five. Similarly, five-point response range is used to gauge in which a company performed effectively in product, organizational, process and advertising innovation, based on one for strongly disagreement and 5 for strong agreement. A total of 14 IPR measurement indicators were created.

\section{Results and discussion}

\subsection{Measurement Model Justification}

Unidimensionality, reliability of an indicator, convergent validity, and internal consistency reliability and discrimination validity were examined in the following measurements produced in this research [27, 28]. As PLS-SEM cannot determine unidimensionality directly, each SMP, IPR, and EST construct will be tested independently via Confirmatory Factor Analysis (CFA) method in SPSS 25. The results have shown that just one component is used in each set of indicator variables other than an eco-efficiency construct Itl2. The results of Itl2 are further examined to examine the item with a poor correlation with other items and low loading factor, which may be removed in the second analysis run. The Itl2.1 indication is therefore deleted from the 2nd test and the consequence seems unifactorial. For additional validation analyses in SmartPLS, the remaining indications were evaluated. Table 1 shows the results.

Table 1 Measurement Model Outcomes

\begin{tabular}{|l|c|c|c|c|}
\hline Constructs & Loading ( $\mathbf{1}^{\text {st }}$ order $)$ & Loading (2nd order ) & AVE & CR \\
\hline Internal SMP & & & 0.72 & 0.88 \\
\hline Cleaner creation & $0.54-0.84$ & 0.84 & 0.59 & 0.88 \\
\hline Employee relation & $0.73-0.87$ & 0.83 & 0.68 & 0.91 \\
\hline Eco-efficiency & $0.62-0.87$ & 0.85 & 0.61 & 0.88 \\
\hline External SMP & & & 0.63 & 0.92 \\
\hline Supplier relation & $0.77-0.88$ & 0.81 & 0.72 & 0.95 \\
\hline Community relation & $0.73-0.91$ & 0.75 & 0.68 & 0.93 \\
\hline Customer relation & $0.76-0.84$ & 0.74 & 0.64 & 0.93 \\
\hline Industrial relation & $0.68-0.82$ & 0.83 & 0.59 & 0.88 \\
\hline Closed-loop production & $0.76-0.88$ & & 0.66 & 0.94 \\
\hline Economic sustainability & $0.73-0.89$ & & 0.66 & 0.94 \\
\hline IPR1 Products innovation & $0.77-0.92$ & & 0.72 & 0.94 \\
\hline IPR2 Processes innovation & $0.83-0.88$ & & 0.73 & 0.96 \\
\hline IPR3 Managerial innovation & $0.82-0.91$ & $0.78-0.87$ & 0.96 \\
\hline IPR4 Advertising innovation & 0.78 & 0.95 \\
\hline \multicolumn{2}{|c|}{ Note: Composite reliability (CR), Average variance extracted (AVE) } & & \\
\hline
\end{tabular}

In mutually the 1st and the 2nd order models, all the factor loadings are over the minimal threshold value of 0.50 [29] and therefore demonstrate each construction's indicator reliability in the measuring model. Likewise, all the composite reliability values and the average variance retrieved have been substantially higher than the minimum necessary levels of 0.60 and 0.50 and consequently the reliability and convergence for each construct is confirmed by the data [27,28]. Meanwhile, the results confirmed the discriminant validity of all buildings grounded on the analyses of the FornellLacker principle, as their AVEs exceed the conforming inter-construct squared correlations [30].

The final IPR, SMP and EST data set comprises of 48 indicator variables from 140 instances, which are suitable for additional structural model analysis after confirmation on the reliability and validity of measuring model. 


\subsection{Structural Model Valuation}

This research assessed structural model according to various criteria, such as determination coefficients $\left(\mathrm{R}^{2}\right)$, predictive relevance $\left(Q^{2}\right)$ and path coefficients $(\beta)$.The $R^{2}$ value 0.51 over a specified minimum value of 0.1 [31] is indicative of partial of the alteration of an EST, showing the model's significant justification. The implication level of route constants is established using a resampling bootstrap technique with 2000 sub-samples. The entire impact on EST (c=0.41, $\mathrm{p}<0.01$ ) by internal SMP is substantial, which supports H1A, as reported in Table 2. The results indicate that the adoption of techniques of pollution control, clean technology and sustainable human resources are linked to improved business efficiency and increased economic and marketplace enactment.

Table 2 EST, IPR and Structural model of internal SMP Consequences

\begin{tabular}{|l|c|c|c|}
\hline Structural path & $\boldsymbol{\beta}^{\mathbf{a}}$ & $\mathbf{R}^{\mathbf{2}}$ & $\mathbf{Q}^{\mathbf{2}}$ \\
\hline SMP (Internal) $\rightarrow$ EST ( path c ) & $0.41^{* * *}$ & 0.51 & 0.32 \\
\hline SMP (Internal) $\rightarrow$ IPR ( path a ) & & & \\
\hline Result variable : IPR1 : Product & 0.12 & 0.28 & 0.18 \\
\hline IPR2 : Process & $0.22^{* *}$ & 0.32 & 0.26 \\
\hline IPR3 : Organizational & $0.18^{*}$ & 0.41 & 0.28 \\
\hline IPR4 : Marketing & $0.17^{*}$ & 0.32 & 0.23 \\
\hline IPR $\rightarrow$ EST ( path b ) & 0.51 & 0.32 & \\
\hline Causative Variable : IPR1 : Product & $0.36^{* * *}$ & & \\
\hline IPR2 : Process & $0.24^{* * *}$ & & \\
\hline IPR3 : Organizational & $0.16^{*}$ & & \\
\hline IPR4 : Marketing & 0.11 & & \\
\hline SMP (Internal) $\rightarrow$ EST ( path ) & $0.31^{* * *}$ & 0.51 & 0.32 \\
\hline
\end{tabular}

${ }^{* * *} \mathrm{p}<0.01,{ }^{* *} \mathrm{p}<0.05,{ }^{\mathrm{a}}{ }^{*} \mathrm{p}<0.1,{ }^{\mathrm{b}} \mathrm{R}^{2}$ standards signify the clarified inconsistency for the endogenous variables ${ }^{c} Q^{2}>0$ specifies that model has extrapolative significance, $Q^{2}<0$ suggests that, Model is deficient extrapolative significance

Notwithstanding the inside SMP significantly affect simply the three conjectured media variable (say: advancement in measures $(\mathrm{a}=0.22, \mathrm{p}<0.05)$, association's development $(\mathrm{a}=0.18, \mathrm{p}<0.1)$, and market development $(\mathrm{a}=0.17$, $\mathrm{p}<0.1)$, though item development $(b=0.36, p<0.01)$. The immediate consequence of the IPR-controlling internal SMP on EST stands determined at $=0.31, \mathrm{p}<0.01$. Internal SMP had a 0.05 and a 0.03 aberrant impact (ab) on SD by means of interaction and authoritative advancement. Contrary to hierarchical advancement, 95\% of bootstrapped trust ranges don't contain zero, and thusly is genuinely critical, the aberrant impact of Internal SMP on EST through measure development. As also genuinely critical is the immediate course from interior SMP to EST, the impacts of internal SMP on EST must be halfway intervened by development of the cycle. Based on the information, H2A is halfway upheld, which propose the extensive intercession consequence of IPR on the relationship of internal SMP with EST. For 95\% bootstrapped certainty stretch, conversely with authoritative advancement, the backhanded impact on EST by internal SMP on concluded measure development do exclude nil and therefore is measurably critical. Meanwhile the immediate way to EST from internal SMP is furthermore genuinely critical, the impact on EST by Internal SMP remain just incompletely interceded by measure advancement? In light of the outcomes, H2A, hypothesizing the critical intervention impact of innovation performance (IPR) on the connection among interior EST and SMP, is somewhat upheld. The outcomes show that the accomplishment of upgrading the way where merchandise can be constantly fabricated as a result of an enormous degree of the inside carrying out of SMP would increment economic performance.

The interrelationships between external SMP, IPR and EST show unforeseen outcomes. Outcome shows the impact on EST by external SMP ( $c=0.11, p>0.1$ ), dismissing H1B, is thusly not huge regarding Table 3 . The aftereffects of this examination show that between organization collaboration, pointed toward working on friendly and ecological maintainability, don't add to helpful financial outcomes. The outer gatherings as opposed to the actual organization have gotten large numbers of the advantages from this external SMP. 
Table 3 External SMP's Structural Model, EST, and IPR results

\begin{tabular}{|l|c|c|c|}
\hline Structural path & $\boldsymbol{\beta}$ a & $\mathbf{R 2} \mathbf{~ b}$ & $\mathbf{Q 2} \mathbf{~}$ \\
\hline SMP (External) $\rightarrow$ EST ( path c ) & 0.11 & 0.51 & 0.34 \\
\hline SMP (External) $\rightarrow$ IPR ( path a ) & & & \\
\hline Decision variable : IPR1 : Product & $0.43^{* * *}$ & 0.27 & 0.18 \\
\hline IPR2 : Process & $0.37^{* * *}$ & 0.32 & 0.24 \\
\hline IPR3 : Organizational & $0.46^{* * *}$ & 0.41 & 0.28 \\
\hline IPR4 : Marketing & $0.45^{* * *}$ & 0.32 & 0.23 \\
\hline IPR $\rightarrow$ EST ( path b ) & & 0.51 & 0.34 \\
\hline Causative variable: IPR1 : Product & $0.38^{* * *}$ & & \\
\hline IPR2 $:$ Process & $0.24^{* * *}$ & & \\
\hline IPR3 : Organizational & $0.16^{*}$ & & \\
\hline IPR4 : Marketing & -0.11 & & \\
\hline SMP (External) $\rightarrow$ EST ( path ) & $-0.18^{* *}$ & 0.51 & 0.32 \\
\hline
\end{tabular}

Although the external SMP have substantial impact on wholly IPR dimensions, namely products $(\mathrm{a}=0.43, \mathrm{p}<0.01)$, processes $(\mathrm{a}=0.37, \mathrm{p}<0.01$ ), managerial $(\mathrm{a}=0.46, \mathrm{p}<0.01)$ and Advertising innovation $(\mathrm{a}=0.45, \mathrm{p}<0.01)$, in external SMP control, EST, i.e. products innovation ( $b=0.38, p<0.01$ ) have only substantial possessions in three dimensions. Indirect effects of external SMP are $0.16,0.10$ and 0.08 correspondingly on EST over process, product and managerial innovation. Although there is a substantial estimated direct influence on IPR control (EST) on external SMP, the estimated value $(=-0.18, \mathrm{p}<0.05)$ is negative, which means that inconsistent mediation is possible. With $95 \%$ sureness intermission booted, the sole unintended consequence of external SMP on EST via process and product improvements does not cover zero. Since there is also statistically significant direct route from an external SMP to EST, the impacts of an external SMP on EST remain solitary partly interceded by process and products improvements. H2B is therefore partially supported, which postulates the important mediating impact of the IPR on the relationship among EST and external SMP. Although the long-term economic benefit provided by socially responsible practices [32] has not been very beneficial to short-term financial success. There might be substantial costs of fulfilling through ecological legislation or finest sustainable practice $[33,34]$. Several companies have thought that there are substantial long-term connections between financial success and sustainability commitment [33]. Dividing overall effect into direct and indirect effects, the findings suggest that such initiatives will encourage better success in product and processes innovation, eventually enhancing the SE while participating in and putting the welfares of exterior stakeholders straight into undesirable profitable outcomes

\section{Conclusion}

In this research the impact of both SMP kinds on EST will be analysed. Although the data show that the internal SMP relay to EST favourably, the exterior SMP and EST have no meaningful link. The results, however, showed that the external and internal SMP both have indirect and direct impacts on EST when IPR is included on these connections. The link among EST and internal SMP is mediated by processes innovation. While managing inner relations and processes proactively in a sustainable way will enhance working and occupational performance directly, these exertions will encourage improved performance in the use of new production techniques and procedures leading to enhancements in EST.

The interrelationships between IPR, external SMP and EST are interesting consequences. The division into direct and indirect impacts of the negligible overall repercussions, environmental and business products, together with social responsibility, via aggressive adoption of external SMP, might lead directly to poor economic outcomes. However, improving the EST indirectly would be possible through improving performance in product and process improvements. External SMP that support external integration and cooperation with a number of stakeholders, including clients and suppliers, are used to promote and share organizationally important information, knowledge and skills with high speed, 
accuracy and efficiency amongst individual members. In a variety of aspects supporting product and processes innovation success, fruitful distribution of important info between associates can be realized, for example quick responses to marketplace variations, and technological progress and a healthier sympathetic of the requirements of the clients, society and suppliers as a whole. While new goods are successfully introduced, they provide better market prospects and higher profitability, improvements in the way products are produced may cut cost and delivery time, and enhance quality and productivity.

The results of this investigation have a number of practical and theoretical consequences. Hypothetically, although the research provides empirical data concerning interrelationships between IPR, SMP and EST and contributes to body of knowledge, the capacity to test such relationship at the same time is useful for a healthier sympathetic of the occurrences. Outcomes of the research have important consequences for industry practitioners, on the other hand. In general, the reestablishment of company strategies can increase economic performance through introduction and implementation of more socially responsible and environmentally friendly activities. Although recognized in the literature the relevance of external SMP, external SMP alone might adversely influence economic performance. It is therefore advised that companies should definitely take use of economic possibilities acquired from being environmentally friendly and informally accountable instead of stand-in on well-meaning emotions or reacting to outer pressures. The execution of external SMP can lead indirectly to improved performance in EST, with a significant performance for product and processes innovation. The link between SMP and EST is also mediated by processes innovation. Therefore, companies should take great account of firming their novelty skills by implementing the sustainable practices, in particular in supply of new products for markets and in the development or improvement of production processes to improve economic performance, in accordance with the statistical evidence.

\section{Compliance with ethical standards}

\section{Acknowledgments}

The Author sincerely appreciate the support of fabricators from Pakistan. They helped the author to make this research possible.

\section{References}

[1] Smith L, Ball P. Steps towards sustainable manufacturing through modelling material, energy and waste flows. International Journal of Production Economics. 2012; 140: 227-238.

[2] Yang MG. Developing a focal firm's sustainable supply chain framework: Drivers, orientation, practices and performance outcomes. University of Toledo. 2013.

[3] Yang CL, Lin SP, Chan YH, Sheu C. Mediated effect of environmental management on manufacturing competitiveness: An empirical study. International Journal of Production Economics. 2010; 123: 210-220.

[4] Kim ST. Implementation of green supply chain management: Impact on performance outcomes in small and medium-sized electrical and electronic firms. University of Nebraska. 2010.

[5] Saleh M, Zulkifli N, Muhamad R. Looking for evidence of the relationship between corporate social responsibility and corporate financial performance in an emerging market. Asia-Pasific Journal of Business Administration. 2011; 3(2): 165-190. OECD. Eco-innovation in industry: Enabling green growth, OECD Publishing. 2010.

[6] OECD. Eco-innovation in industry: Enabling green growth, OECD Publishing. 2010.

[7] Madu CN. Handbook of environmentally conscious manufacturing. Massachusetts, US: Kluwer Academic Publishers. 2001.

[8] Allwood J. What is sustainable manufacturing? Sustainability: What are the issues? In: Sustainable Manufacturing Seminar Series; February. 2005.

[9] US Department of Commerce. Promoting competitiveness: Partnerships and progress of the office of manufacturing and services. International Trade Administration. 2007.

[10] Jayal AD, Badurdeen, F Jr. OWD, Jawahir IS. Sustainable manufacturing: Modeling and optimization challenges at the product, process and system levels. CIRP Journal of Manufacturing Science and Technology. 2010; 2(3): 144152 . 
[11] Jawahir IS, Dillon Jr O. Sustainable manufacturing processes: New challenges for developing predictive models and optimization techniques. In: 1st International Conference on Sustainable Manufacturing. Montreal, Canada. 2007.

[12] Barney J. Firm resources and sustained competitive advantage. Journal of Management. 1991; 17: 99-120.

[13] Montabon F, Sroufe R, Narasimhan R. An Examination of corporate reporting, environmental management practices and firm performance. Journal of Operations Management. 2007; 25(5): 998-1014.

[14] Oeyono J, Samy M, Bampton R. An examination of CSR and financial Performance: A study of the top 50 Indonesian listed corporations. Journal of Global Responsibility. 2011; 2: 100-112.

[15] Zailani S, Jeyaraman K, Vengadasan G, Premkumar R. Sustainable supply chain management (SSCM) in Malaysia: A survey. International Journal of Production Economics. 2012; 140: 330-340.

[16] de Bussy NM, Suprawan L. Most valuable stakeholders: The impact of employee orientation on corporate financial performance. Public Relations Review. 2012; 38(2): 280-287.

[17] Brio JA, Fernandez E, Junquera B. Management and employee involvement in achieving an environmental actionbased competitive advantage. International Journal of Human Resource Management. 2007; 18: 491-522.

[18] Pagell M, Gobeli D. How Plant managers' experiences and attitudes toward sustainability relate to operational performance. Production and Operations Management. 2009; 18(3): 278-299.

[19] Gallardo-Vazquez D, Sanchez-Hernandez MI. Measuring corporate social responsibility for competitive success at a regional level. Journal of Cleaner Production. 2014; 72: 14-22.

[20] Rao P, Holt D. Do green supply chains lead to competitiveness and economic performance? International Journal of Operations \& Production Management. 2005; 25(9): 898-916.

[21] Talbot S, Lefebvre E, Lefebvre LA. Closed-loop supply chain activities and derived benefits in manufacturing SMEs. Journal of Manufacturing Technology Management. 2007; 18(6): 627-658.

[22] Spencer JW. Firm's knowledge sharing strategies in the global innovation system: Empirical evidence from the flat panal display industry. Strategic Management Journal. 2003; 24(3): 217-233.

[23] Chong AYL, Chan FTS, Ooi KB, Sim JJ. Can Malaysian firms improve organizational/innovation performance via SCM? Industrial Management \& Data Systems. 2011; 111(3): 410-431.

[24] Varis M, Littunen H. Types of innovation, sources of information and performance in entrepreneurial SMEs. European Journal of Innovation Management. 2010; 13(2): 128-154.

[25] Otero-Neira C, Lindman MT, Fernandez MJ. Innovation and performance in SME furniture industries: An international comparative case study. Marketing Intelligence \& Planning. 2009; 27(2): 216-232.

[26] Cheng, CCJ, Yang CL, Sheu C. The link between eco-innovation and business performance. A Taiwanese industry context. Journal of Cleaner Production. 2014; 64: 81-90.

[27] Urbach N, Ahlemann F. Structural equation modeling in information systems research using partial least squares. Journal of Information Technology - Theory and Application. 2010; 11(2): 5-40.

[28] Hair JF, Hult GTM, Ringle CM, Sarstedt M. A Primer on partial least squares structural equation modeling. LA: Sage Publication Inc. 2014.

[29] Hair JF. Multivariate Data Analysis. 6th ed. New Jersey: Pearson Prentice Hall. 2006.

[30] Fornell C, Larcker D. Evaluating structural equation models with unobservable variables and measurment error. Journal of Marketing Research. 1981; 18: 39-50.

[31] Falk RF, Miller NB. A primer for soft modelling. Ohio: The University of Akron. 1992.

[32] Lin CH, Yang HL, Liou DY. The impact of corporate social responsibility on financial performance: Evidence from business in Taiwan. Technology in Society. 2009; 31: 56-63.

[33] Smith L, Ball, P. Steps towards sustainable manufacturing through modeling material, energy and waste flows. International Journal of Production Economics. 2012; 140: 227-238.

[34] Krumwiede D, Hackert AM, Tokle J, Vokurka RJ.The Practice of corporate social responsibility in different countries: A study of firms in Canada, Hungary, Italy, Lebanon, Taiwan and the United States. International Journal of Management. 2012; 29: 389-401. 